\title{
The influence of antecedent conditions on flood risk in sub-Saharan Africa
}

\author{
Konstantinos Bischiniotis ${ }^{1}$, Bart van den Hurk ${ }^{1,2}$, Brenden Jongman ${ }^{1,3}$, Erin Coughlan de Perez ${ }^{1,4,5}$, Ted Veldkamp ${ }^{1}$, \\ Hans de Moel ${ }^{1}$, and Jeroen Aerts ${ }^{1}$ \\ ${ }^{1}$ Institute for Environmental Studies, Vrije Universiteit Amsterdam, 1081 HV Amsterdam, the Netherlands \\ ${ }^{2}$ Royal Netherlands Meteorological Institute (KNMI), De Bilt, 3731 GA, the Netherlands \\ ${ }^{3}$ Global Facility for Disaster Reduction and Recovery (GFDRR), World Bank, Washington DC, USA \\ ${ }^{4}$ International Research Institute for Climate and Society, Columbia University, Palisades, NY 10964, USA \\ ${ }^{5}$ Red Cross Red Crescent Climate Centre, The Hague, $2521 \mathrm{CV}$, the Netherlands
}

Correspondence: Konstantinos Bischiniotis (kbischiniotis@gmail.com)

Received: 1 February 2017 - Discussion started: 17 February 2017

Revised: 16 November 2017 - Accepted: 28 November 2017 - Published: 19 January 2018

\begin{abstract}
Most flood early warning systems have predominantly focused on forecasting floods with lead times of hours or days. However, physical processes during longer timescales can also contribute to flood generation. In this study, we follow a pragmatic approach to analyse the hydrometeorological pre-conditions of 501 historical damaging floods from 1980 to 2010 in sub-Saharan Africa. These are separated into (a) weather timescale ( $0-6$ days) and (b) seasonal timescale conditions (up to 6 months) before the event. The 7-day precipitation preceding a flood event (PRE7) and the standardized precipitation evapotranspiration index (SPEI) are analysed for the two timescale domains, respectively. Results indicate that high PRE7 does not always generate floods by itself. Seasonal SPEIs, which are not directly correlated with PRE7, exhibit positive (wet) values prior to most flood events across different averaging times, indicating a relationship with flooding. This paper provides evidence that bringing together weather and seasonal conditions can lead to improved flood risk preparedness.
\end{abstract}

\section{Introduction}

In recent decades, weather-related disasters have accounted for about $90 \%$ of all natural disasters (UNISDR, 2015). There is an upward trend in disaster loss, which is driven by global climate change and the increasing concentration of populations and economic assets in flood-prone areas
(Bouwer et al., 2007; Prenger-Berninghoff et al., 2014). Flooding affects millions of people across the globe each year. Between 1980 and 2012 the average annual reported losses and fatalities due to floods exceeded USD 23 billion and 5900 people, respectively (EM-DAT, 2014; Jongman et al., 2015).

Flood risk management has traditionally focused on longterm flood protection techniques such as levees and dams (Kellet and Caravani, 2013). Today, people employ complex combinations of flood risk strategies, ranging from technical flood protection measures to financial compensation mechanisms such as insurance, as well as nature-based solutions (Aerts et al., 2014). Lower-income countries often cannot afford to implement preventive measures, mainly due to the high investment costs (e.g. Douben, 2006). Consequently, they are more reliant on post-disaster response and preparedness activities, often assisted by international donors and humanitarian organizations.

The role of science in disaster risk reduction has been globally recognized in the Sendai Framework (UNISDR, 2015). Preparedness activities and flood forecasting have received increasing attention and have led to new sciencebased early action systems (Coughlan de Perez et al., 2014). Weather forecasts, with typical lead times of some hours or days, have become the basis of such systems (Alfieri et al., 2012), and they have played an important role in reducing flood impacts not only in developed countries (Rogers and Tsirkunov, 2010) but also in several lower-income ones 
(Golnaraghi, M. 2012; Webster, 2013). Therefore, research stresses the importance of their improvement. For example, the devastating 2010 Pakistan floods could have been predicted 6-8 days in advance if quantitative precipitation forecasts had been available, providing sufficient time for reaction (Webster et al., 2011).

On longer timescales, seasonal forecasts have been used in early warning and early action systems. A seasonal forecast was used to successfully prepare for floods in West Africa by the International Federation of Red Cross and Red Crescent Societies (IFRC) (Tall et al., 2012; Braman et al., 2013). With regard to floods, seasonal forecasts are used for signaling a likelihood of increased precipitation. Recently, the ECMWF System 4 seasonal precipitation forecast has shown higher predictive skill than climatology for the Niger, Blue Nile and Limpopo basins (Dutra el al., 2013; Seibert et al., 2017), and advances have been achieved in prediction skill and resolution for seasonal precipitation in western Ethiopia (Zhang et al., 2017). However, Stephens et al. (2015) showed that mean monthly precipitation is not well correlated with global floodiness, demonstrating the shortcomings of using seasonal precipitation as a proxy for flood hazard by itself and stressing the importance of modelling the hydrological systems before issuing warnings based on precipitation forecasts.

Depending on the region, factors other than precipitation can also play a role in flood generation. For instance, evapotranspiration and soil saturation are considered important in flood forecasting (Sivapalan et al., 2005; Merz et al., 2006; Parajka et al., 2010; Fundel and Zappa, 2011). Reager et al. (2014) demonstrated that basin-scale estimates of total water storage, including soil moisture, could be used to characterize regional flood potential for the Missouri 2011 floods several months in advance. Floodiness in southern and eastern Africa also showed strong correlations with seasonal average soil moisture (Coughlan de Perez, 2017), and the large role of antecedent moisture, rather than high rainfall, was demonstrated by Schröter et al. (2015) on the June 2013 floods in Germany. These physical factors are likely to influence the length of the flood build-up period, which can range from a few days to several months before an event (Nied et al., 2014). So, as forecast skills are inversely proportional to lead time (Molteni et al., 2011), the likelihood of needlessly taking action against flood risk increases with longer warning lead times. This requires further research on weather and seasonal flooding drivers that may lead to improved flood preparedness.

This study assesses the role of the antecedent conditions on short to long timescales prior to flood generation. We investigate what conditions often preceded major flood events, offering insights on how to extend lead times for preparedness by relying on observational systems. For that, we take into account reported damaging flood events from 1980 to 2010 in sub-Saharan Africa. We discuss the potential role of seasonal-scale indicators complementary to the weather- scale phenomena for indicating an increased flooding likelihood. More specifically, we analyse the correlation between floods and hydro-meteorological variables, both on a weather (0-6 days before each flood event), and on a seasonal timescale (up to 6 months before each flood event). Weather-scale conditions are evaluated by the 7-day precipitation (PRE7) that preceded the flood event. Seasonal-scale conditions were drawn from the standardized precipitation evapotranspiration index (SPEI). Although SPEI has been applied in studies focusing on seasonal drought forecasting (Mossad and Alazba, 2015; Xiao et al., 2017), we argue that it could also be used in flood monitoring and forecasting. The findings of this study contribute to the emerging literature on this topic (Goddard et al., 2014; White et al., 2015) and may be of use to humanitarian organizations and decision makers for preventive flood risk management planning.

The remainder of this paper is structured as follows. Section 2 outlines the methodological framework and the data used in the analysis. Section 3 presents the results. Section 4 discusses the findings and the limitations of the study, including suggestions for further research. Section 5 provides a brief conclusion.

\section{Methodology}

Figure 1 shows the different steps in the approach taken by this study. The analysis is based on damaging flood events in sub-Saharan Africa from 1980 to 2010 that are reported in the NatCatSERVICE database (Munich Re, 2014). We assessed both independently and jointly the antecedent weather and climate conditions in the locations of reported floods using two indicators: (a) the short-memory anomaly ("weather-scale") evaluated by the cumulative rainfall over the 7 days preceding the event (PRE7), and (b) the longmemory anomaly ("seasonal-scale") reflected in the SPEI for the preceding 1, 3 and 6 months (SPEI1, SPEI3, SPEI6).

\subsection{Datasets and their limitations}

\subsubsection{Study area and reported floods}

We used the NatCatSERVICE, a natural disaster database maintained by Munich Reinsurance Company (Munich Re, 2014) to identify the reported flood events in sub-Saharan Africa. This area includes many flood-prone countries (UNISDR, 2015), which lack hard protective infrastructure against flooding. Hence, early warning and timely preparation play an important role in risk reduction. Events in the database are entered on a country level when there is property damage and/or there are people affected (injured, dead). So, not all the hydrologically defined floods (i.e. unusually high discharges and peak water levels) fulfil the entry criteria in the insurance databases. Hence, many hydrological floods are likely not included in the database as they did not cause any severe damage. By taking into account only the 


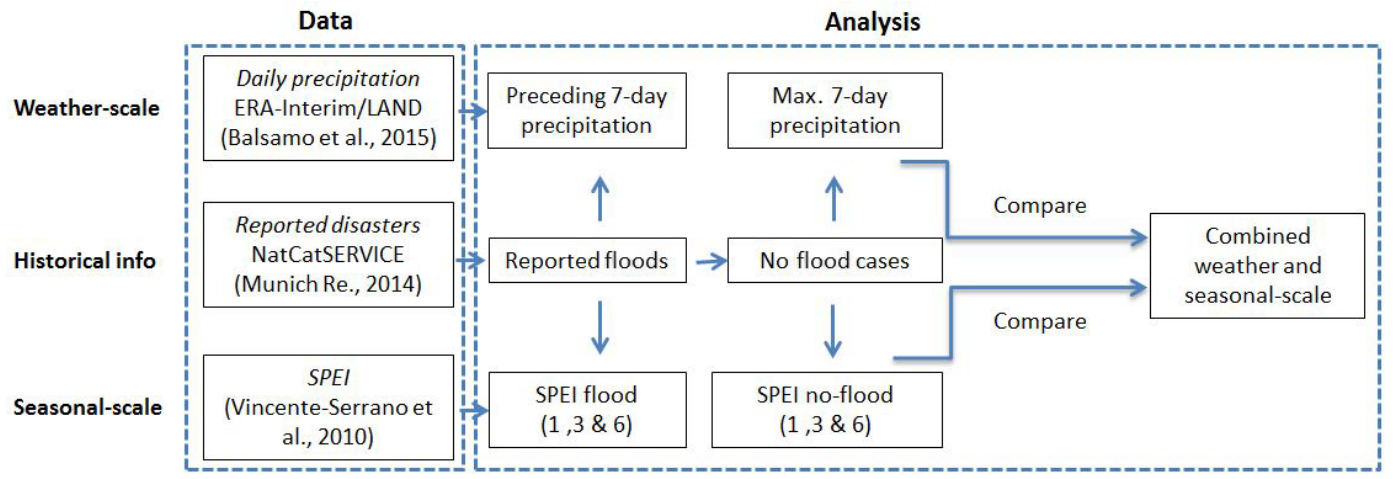

Figure 1. Schematic overview of the approach followed in this study.

damaging events, we expect the research will be especially useful to the humanitarian sector. Recorded information includes fatalities, affected population, economic losses, onset and end dates and a pair of coordinates of each event. The sources of the database include national insurance agencies, online databases from news agencies, governmental and non-governmental organizations, and a worldwide network of scientific and insurance contacts (Tschoegl et al., 2006). NatCatSERVICE is a widely applied reference database in scientific studies (e.g. Hoeppe, 2016; Jongman et al., 2014).

The NatCatSERVICE data include two categories of inland flooding: (a) riverine floods and (b) flash floods. This study focused on riverine floods, as flash floods usually have a smaller extent, shorter build-up period and antecedent conditions play a less important role in their generation (Nied et al., 2014). We identified 501 damaging reported riverine flood events in sub-Saharan Africa between 1980 and 2010. Figure 2 shows the number of reported floods and the economic losses caused by these floods per year. The upward trend in flood number over time could be attributed to increased exposure due to population growth and urbanization (Jongman et al., 2012) and under-reporting of events in the earlier years due to limited penetration of communication technology (Kron et al., 2012).

\subsubsection{Daily precipitation}

Daily precipitation was derived from the European Centre for Medium-Range Weather Forecasts (ECMWF) global reanalysis of land-surface parameters, ERA-Interim/Land, from 1980 to 2010 (Balsamo et al., 2015) (available online at http://apps.ecmwf.int/datasets/). The gridded daily time series were extracted at $2.5^{\circ} \times 2.5^{\circ}$ horizontal resolution. This large resolution was chosen (a) because it corresponds to the average flooded areas $\left(64000 \mathrm{~km}^{2}\right)$ (Douben, 2006), and (b) to reduce the likelihood of possible errors in the reported coordinates from the NatCatSERVICE database.

\subsubsection{Standardized precipitation evapotranspiration index}

The SPEI, developed by Vicente-Serrano et al. (2010), was used to evaluate the antecedent soil conditions before the reported flood events. The SPEI is a normalized variable for a long time series of at least 50 years, comparing monthly net precipitation totals (precipitation minus potential evapotranspiration) with their long-term means over different timescales (1, 3, 6 or 12 months). An $x$-month SPEI (e.g. SPEI for January 1984) provides a comparison with the same $x$-month conditions (e.g. SPEI for all other January's between 1980 and 2010) for all years in the historical record. Shorter accumulation periods (1 month) represent surface soil water content, while longer ones $(3,6,12$ months) indicate the subsurface state (e.g. soil moisture, groundwater discharge) (Du et al., 2013). Unlike the standardized precipitation index (SPI), the SPEI takes potential evapotranspiration into account, which can consume a large portion of total rainfall (Abramopoulos et al., 1988). Precipitation and evapotranspiration together largely determine soil moisture variability, and thus indirectly affect the flood build-up period through links between soil moisture, river discharge and groundwater storage (Vicente-Serrano et al., 2010). Although some studies have successfully applied SPI as a flood indicator (Seiler et al., 2002; Guerreiro et al., 2008), SPEI has not yet been applied.

In this study SPEI values calculated by Vicente-Serrano et al. (2010) have been used. These were first acquired at a $0.5^{\circ} \times 0.5^{\circ}$ spatial resolution (available online at http://sac. csic.es/spei/index.html), and subsequently they were scaled up to $2.5^{\circ} \times 2.5^{\circ}$ resolution by taking the mean value in order to be consistent with the daily precipitation dataset. Mean monthly temperature from the NOAA GHCN_CAMS gridded dataset (Fan and van den Dool, 2008) and mean monthly precipitation from the Global Precipitation Climatology Centre (GPCC) (Schneider et al., 2015) beginning in 1950 were used to estimate the monthly potential evapotranspiration (PET), using Thornthwaite (1948) (see Vicente- 

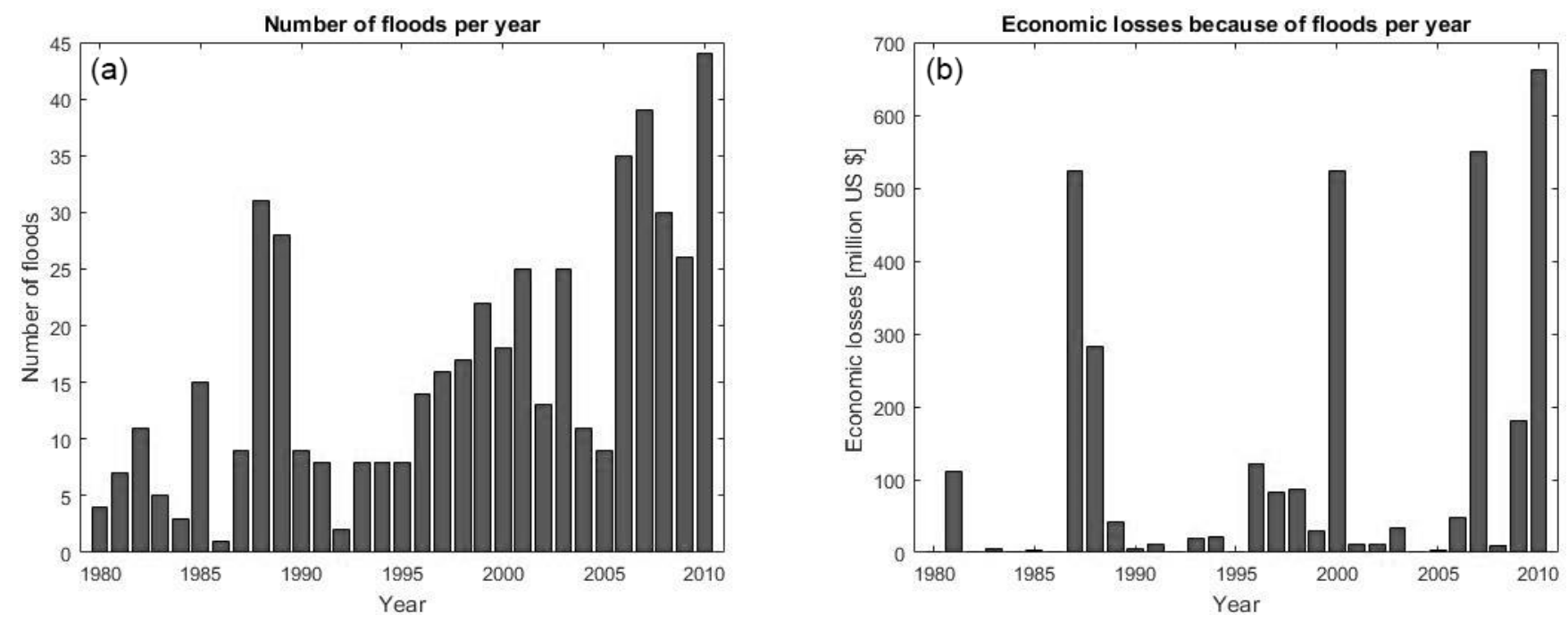

Figure 2. Number of floods per year that are analysed in this study (a) and economic losses in million USD per year caused by these floods (b) in sub-Saharan Africa between 1980 and 2010 (Munich Re, 2014).

Table 1. Classification of SPEI values (based on Edossa et al., 2014).

\begin{tabular}{ll}
\hline SPEI class & Class description \\
\hline$\leq-2$ & Extremely dry \\
$-2:-1.5$ & Severely dry \\
$-1.5:-1$ & Moderately dry \\
$-1:-0.5$ & Mild dry \\
$-0.5: 0$ & Near normal dry \\
$0: 0.5$ & Near normal wet \\
$0.5: 1$ & Mild wet \\
$1: 1.5$ & Moderately wet \\
$1.5: 2$ & Severely wet \\
$>2$ & Extremely wet \\
\hline
\end{tabular}

Serrano et al., 2010, for more detail on the processing of the SPEI index). The ECMWF's ERA-Interim reanalysis dataset was not used for this as it covers a considerably shorter time span. The SPEI values are given for the end of each calendar month. Positive and negative SPEI values indicate relatively wet and dry periods, respectively (Table 1).

\subsection{Analysis}

\subsubsection{Temporal scale}

An illustrative example of discharge in relation to time, before, during and after a hypothetical flood event is given in Fig. 3. The time points of the different flood phases that were used in the analysis are mentioned. The start date of each flood, as reported in the NatCatSERVICE flood dataset $(\mathrm{Mu}-$ nich Re, 2014), is the end of the "flood build-up" period, dur- ing which we assumed that the physical processes that led to flooding took place (Nied et al., 2014).

The build-up period was divided into two parts: a preconditioning period on the seasonal scale (up to 6 months before the flood onset), and a flood triggering episode of a 7-day duration in the weather-scale period. In this way, we aimed to distinguish between the antecedent conditions that may have led to an increased flooding likelihood from the intense rainfall prior to the event. The build-up period ends with the month before the rainfall event so that the two periods do not overlap. The seasonal-scale period was split into 1-, 3- and 6-month periods, and the SPEIs (SPEI1, SPEI3, SPEI6) with corresponding accumulation time periods were used. SPEI0, which is independent from the seasonal SPEIs, has a 1-month accumulation time period and refers to the flood onset month itself.

\subsubsection{7-day precipitation (PRE7)}

Using ECMWF's ERA Interim/Land dataset, we calculated the 7-day preceding precipitation (PRE7), having as ending point the reported onset date of each flood, as well as the maximum 7-day precipitation (MAX7) during the month that each flood was reported. The length of the precipitation period leading to a flood depends highly on the local characteristics. For example, a 2-day precipitation sum is best correlated with flood frequency and magnitude in the high ranges of the Swiss Alps, but longer-duration precipitation affects flood occurrence more in the western and eastern Swiss Plateau (Froidevaux et al., 2015). Hence, we expect to be on the safe side by using a relatively long synoptic time window (7 days), similarly to Webster et al. (2011).

Subsequently, for each flood, we used its particular onset month and location to identify the maximum 7-day precipi- 


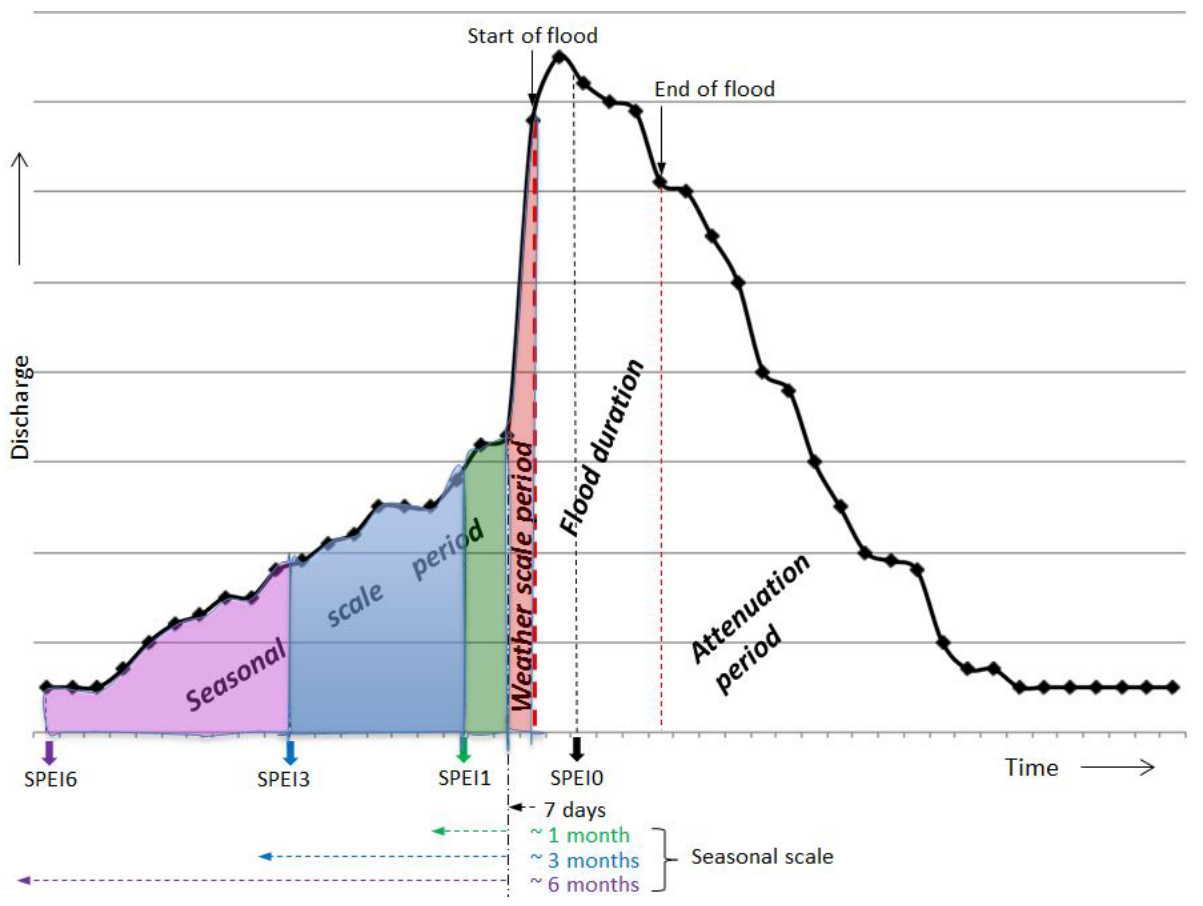

Figure 3. Theoretical discharge before, during and after a hypothetical flood event. Weather-scale period starts 7 days before flood onset date. Seasonal-scale period is split into 1-, 3- and 6-month accumulation periods. It starts 6 months before flood onset date and continues until the last month before the one that includes the 7-day precipitation. SPEI0 is defined as the SPEI over the calendar month in which the flood onset took place.

tation for that month within the other dataset years, in which no flood was reported. Following the way that the SPI is calculated (Mckee et al., 1993), for both PRE7 and MAX7, we used a Gamma distribution to fit the 31 values ( 1 flood and 30 no-floods) over the entire 31-year dataset and we standardized them so that the mean is 0 and the standard deviation 1 . The year with the flood event $(\mathrm{F})$ was labelled differently from the remaining 30 no-flood events (NF). We repeated this procedure for all 501 flood events. Then, we compared PRE7 and MAX7 and we performed a two-tailed $z$ test of unpaired samples to evaluate whether the medians of PRE7 and MAX7 in the case of a flood differed significantly from that of the NF cases.

\subsubsection{Preceding SPEI values and SPEIO}

SPEI values for the months before a flood event are labelled SPEI1, SPEI3 and SPEI6, indicating accumulation timescales of 1, 3 and 6 months, respectively (Fig. 3). These seasonal SPEI values are not independent, as shorter-period SPEIs (e.g. SPEI1, 3) are part of the calculation of longerperiod ones (e.g. SPEI6).

SPEI0 has a 1-month accumulation period and refers to the end of the month that includes the flood's reported start date. So, it is independent of the other SPEIs. This was used to evaluate the wetness at the end of this month and check
Table 2. Parameters for RR calculation.

\begin{tabular}{lccc}
\hline \multirow{2}{*}{ Group } & \multicolumn{2}{c}{ SPEI $>$ threshold } & \\
\cline { 2 - 3 } & Yes & No & Total \\
\hline Floods & $A$ & $C$ & $A+C$ \\
No floods & $B$ & $D$ & $B+D$ \\
\hline
\end{tabular}

whether it could be used as a flood monitoring tool. All month definitions were based on calendar days.

For each of the 501 flood events individually, we used the same flood onset month and the same location in order to get the SPEIs of all the NF cases. Subsequently, we performed a two-tailed $z$ test of unpaired samples to compare the median SPEI values of the different time periods of NF events $(n=$ $15030)$ with those of flood events $(n=501)$.

Then, we calculated the probability of having a flood $(\mathrm{F})$ and the probability of not having a flood (NF) given certain SPEI thresholds (for instance, using all data points corresponding to months with an SPEI3 value larger than 1). In order to enable appropriate comparisons between the two groups, we calculated the risk ratio (RR) or relative risk. This is a relative measure that quantifies the risk of prevalence of one group against another one by taking the ratio of two proportions, i.e. dividing the probability of a flood by the probability of no flood (Morris and Gardner, 1988) (Table 2, 
Eq. 1). The RR is commonly used in medical and epidemiology studies (e.g. Katz, 2006; Shrier and Steele, 2006; Zhang and $\mathrm{Yu}, 1998)$. Although it does not follow a normal distribution, the natural logarithm of the sample is approximately normally distributed to produce the $95 \%$ confidence intervals, which are calculated according to Morris and Gardner (1988) and Daly (1998). Therefore, first, a confidence interval is generated for $\log _{\mathrm{e}}(\mathrm{RR})$ and subsequently the antilog of the upper and lower limits of the confidence interval for $\log _{\mathrm{e}}(\mathrm{RR})$ are computed to give the upper and lower limits of the confidence interval for the RR (Eqs. 2-6). In the case that the upper limit is above 1 and the lower limit below 1 , the $R R$ is not statistically significant:

$\mathrm{RR}=\frac{\frac{A}{A+C}}{\frac{B}{B+D}}$,

$\mathrm{SE}\left(\log _{\mathrm{e}} R\right)=\sqrt{\frac{1}{A}-\frac{1}{A+C}+\frac{1}{B}-\frac{1}{B+D}}$,

$W=\log _{\mathrm{e}} R-\left(1.96 \times \mathrm{SE}\left(\log _{\mathrm{e}} R\right)\right)$,

$X=\log _{\mathrm{e}} R+\left(1.96 \times \mathrm{SE}\left(\log _{\mathrm{e}} R\right)\right)$,

Lower Limit of confidence interval: $e^{\mathrm{w}}$,

Upper Limit of confidence interval: $e^{\mathrm{x}}$.

\subsubsection{Combination of PRE7 and SPEI0 with preceding SPEIs}

In a final assessment, we used the preceding seasonal-scale SPEIs in combination with SPEI0 and PRE7 (denoting conditions at the time of flooding) to calculate the RR of F events and NF events using various SPEI and PRE7 thresholds. In this way, we evaluated the RR by bringing together the preceding seasonal-scale conditions and the conditions during the month of the flood.

\section{Results}

\subsection{Floods in sub-Saharan Africa}

Figure 4 shows the spatial distribution of the 501 selected flood events from 1980 to 2010 and the number of fatalities that have been caused. Most floods were reported in continental sub-Saharan countries. South Africa faced the highest number of reported flood events, followed by Kenya, Somalia, Mozambique and Ethiopia. In southern Africa, a considerable number of floods were reported in the areas of the Limpopo and Zambezi river basins and along the coast of South Africa. Eastern Africa also experienced a significant number of flood events, mainly in the southern part of the Nile and near lakes Turkana and Victoria. In West Africa, there is a concentration of floods along the Volta, Niger and Senegal rivers. The pattern shows consistency with the floods reported by Dartmouth Flood Observatory (available at http://floodobservatory.colorado.edu/), which shows that most recent deadly floods happened in places where the population has increased more rapidly in recent years (Di Baldassarre et al., 2010).

\subsection{Relation of 7-day precipitation to flooding}

Figure 5a presents the standardized 7-day precipitation (PRE7) of flood (F) and no-flood (NF) events. On each boxplot, the central red line is the median and the edges of each box are the 25th and 75th percentiles. The whiskers extend to the most extreme data points, covering $99 \%$ of the values, and the outliers are plotted individually $(+)$. The results of the $z$ test showed that the median of the preceding PRE7 of $\mathrm{F}$ did not exhibit any significant difference with that of NF $(p=0.1)$. This reveals that although PRE7 is high, it cannot explain by itself the generation of the flood. Similar magnitude events, in the same locations and during the same months that floods were reported, occurred without resulting in any (reported) flood.

Figure 5b compares the MAX7 of F events to the MAX7 of NF events. Although it appears that the median of MAX7 was significantly higher than the median of the NF cases ( $p=0.05$ ), we should be aware of the fact that statistical tests tend to find significance when the sample size is large. Nevertheless, the difference between PRE7 and MAX7 implies that these events occur at different moments within the month of the flood, and that the PRE7 value does not always capture the highest precipitation amount within that month. This might be subject to several reasons such as inaccuracies of the reported flood onset date, more precipitation before the PRE7 days, which created flood favourable conditions, or more precipitation after the flood onset date, which contributed to longer flood duration.

However, Fig. 5 also shows that in many occasions very intense precipitation events did not produce any flood, implying that factors other than high precipitation also contributed to flood generation.

\subsection{Relation between SPEI0 and seasonal-scale SPEIs with flooding}

Figure 6 shows the SPEI values of $\mathrm{F}$ and NF events on different timescales (0, 1, 3 and 6 months prior to the flood onset month). For NF events, the median value of SPEI is slightly below zero for all timescales. The median SPEI0-SPEI6 values representing the $\mathrm{F}$ events are significantly higher, which is underpinned by the results of the $z$ tests ( $p$ values $<0.05$ ). More specifically, the median value of SPEI0 for F events exhibits a value close to 1 , which indicates that the wetness in the end of these months was high. The high values found for SPEI0 demonstrate, moreover, that SPEI0 could be used as a flood monitoring tool. Further, the median value of seasonal SPEIs, which are independent of SPEI0, constantly lies in the wet categories $(>0)$, for all the timescales, showing that the wet antecedent conditions have likely played a role in flood 


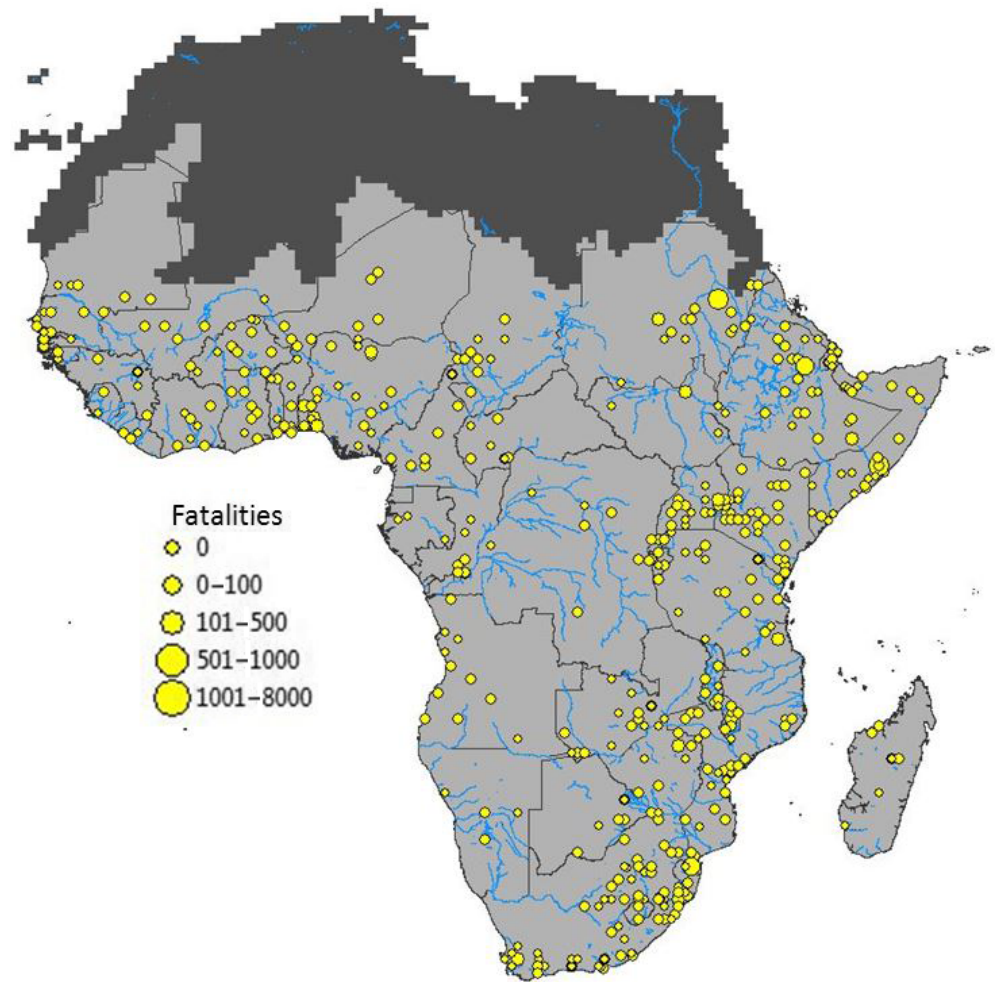

Figure 4. Reported flood events (1980-2010) in sub-Saharan Africa grouped per country. The size of the dots shows the number of fatalities that each flood caused (Munich Re, 2014).
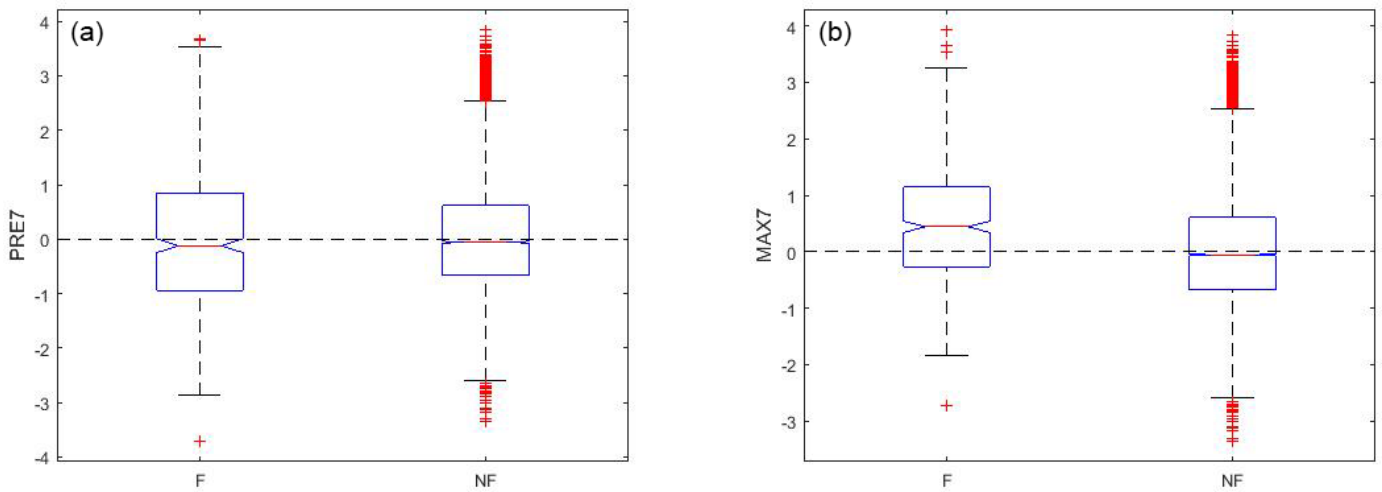

Figure 5. Standardized 7-day preceding precipitation (PRE7; a) and maximum 7-day precipitation (MAX7; b) of flood (F; left bars) and no-flood (NF; right bars) events collected over all 501 reported flood events.

generation. The highest median values are found for SPEI1, followed by SPEI3. The median value of SPEI6 is significantly lower than both of them, showing, finally, that when the accumulation period is longer, the SPEI tends to climatological conditions and flood signals become vaguer. The percentage of floods that exhibit wetter than normal condition (SPEI greater than 0 ) is 78, 70, 65 and $57 \%$ for SPEI0, SPEI1, SPEI3 and SPEI6, respectively.

Figure 7a shows the RR using several exceedance thresholds for the SPEIs, which range from -3 to +3 (horizon- tal axis). A value of 1 denotes equal risk likelihood, while higher values indicate that the risk of $\mathrm{F}$ is higher than the risk of NF. Each line represents SPEI values for the different antecedent times (SPEI0, magenta; SPEI1, red; SPEI3, green; and SPEI6, blue). For each of these lines, the confidence intervals are shown in separate panels (Fig. 7b-e). For SPEI values below -1 , the probability of having an $\mathrm{F}$ event and a NF event is $\sim 1$, irrespective of which SPEI is used. With increasing threshold levels higher than -1 , a slight increase in the RR is observed for the seasonal SPEIs, denoting 


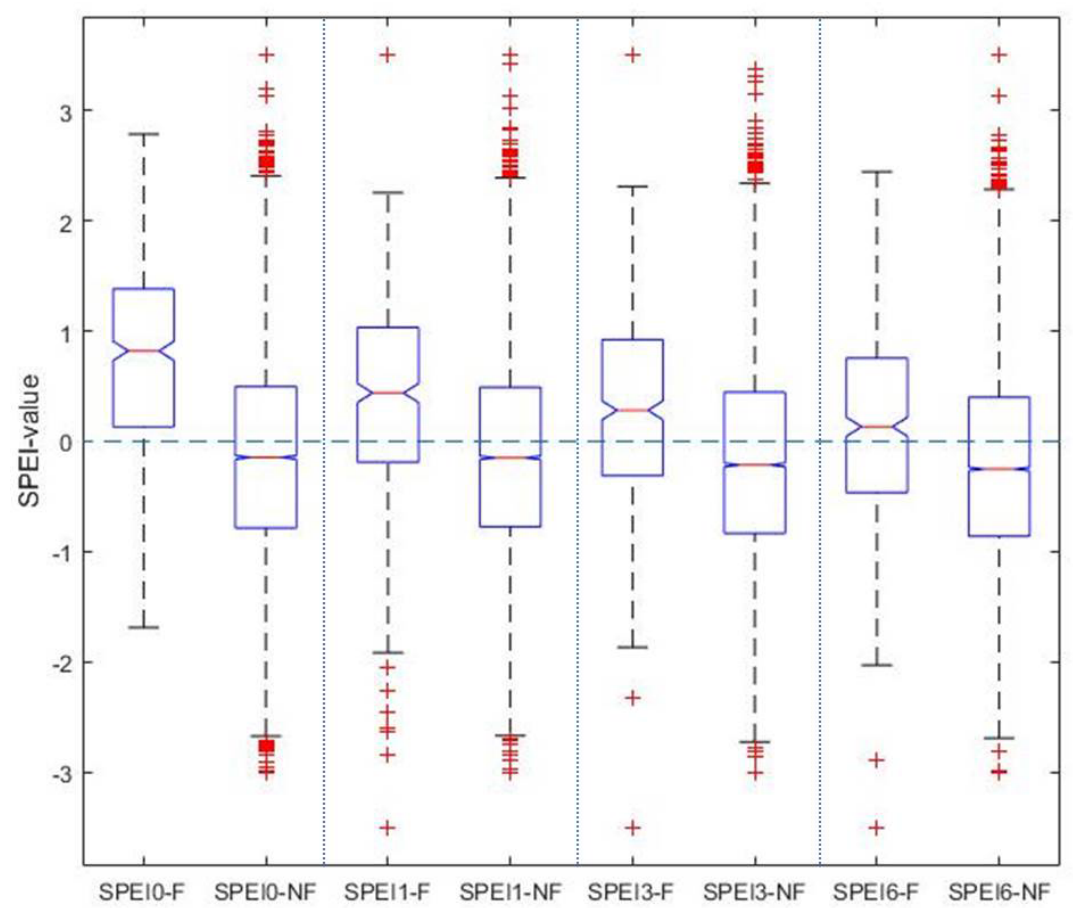

Figure 6. SPEIO and seasonal-scale SPEIs for flood (F) and no-flood (NF) events.

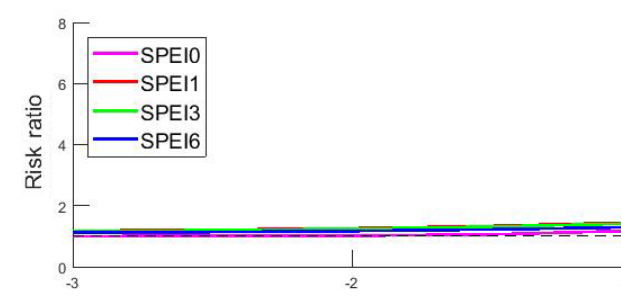

(b) SPEIO

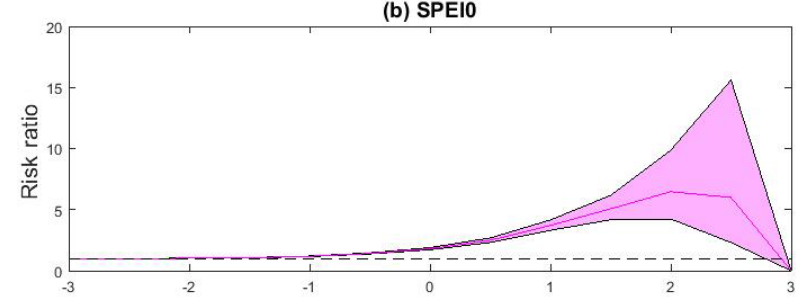

(d) SPEI3

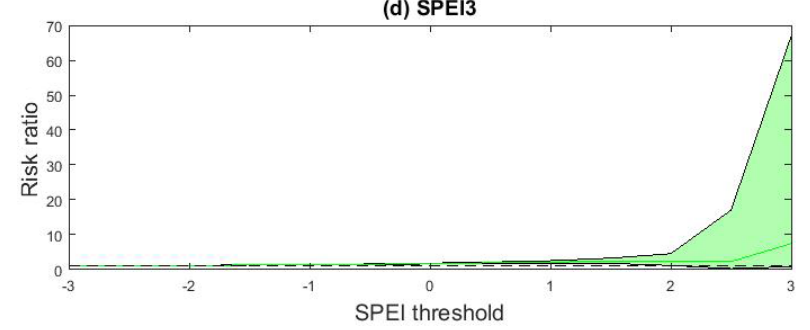

(a) Risk ratio as a function of SPEI thresholds

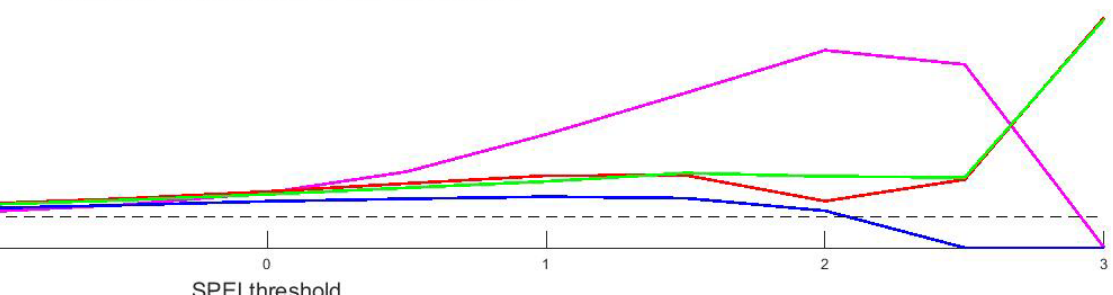

(c) SPEI1

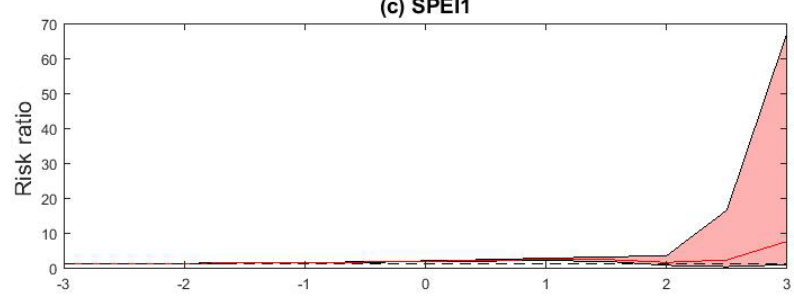

(e) SPEI6

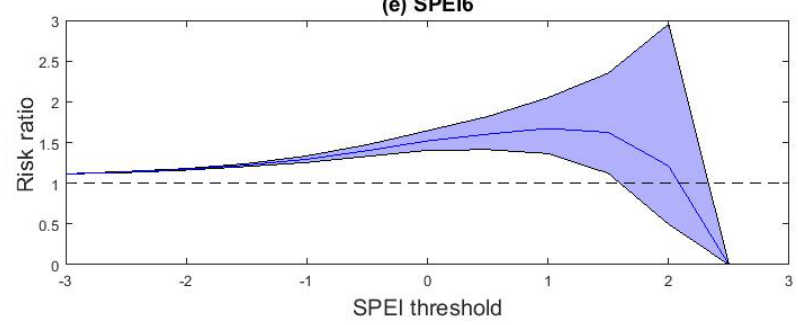

Figure 7. Risk ratio between $\mathrm{F}$ and NF as function of SPEI exceedance values (SPEI0, magenta; SPEI1, red; SPEI3, green; SPEI6, blue) (a), and their confidence intervals (b-e). The horizontal dashed line shows the risk ratio of 1. 
that when hitting these SPEI threshold values the probability of encountering an $\mathrm{F}$ event is relatively higher compared to the probability of encountering a NF event. When looking at SPEI values over 1.5 , it becomes approximately 2.5 times more likely to have a flood when SPEI1 and SPEI3 exceed this threshold. While the SPEI1 and SPEI3 exhibit similar values, the SPEI6 shows considerably lower ratios, indicating that flood events preceded by such a long wet period are few. For the month that the floods were reported (SPEI0), the maximum ratio is reached when looking at SPEI values over 2 , when it becomes 6.5 times more likely to have a flood event. The big difference in the increased probability of flooding of SPEI0 and seasonal SPEIs shows the importance of the hydro-meteorological conditions during the flood onset month. Using thresholds higher than 2 for the seasonal SPEIs does not lead to statistically significant results and the $\mathrm{RR}$ and its uncertainty bounds decrease due to a statistical artifact and missing data.

\subsection{Combination of seasonal-scale SPEIs with SPEI0 and PRE7}

We now discuss the flood probability focusing on the joint occurrence of conditions on the preceding seasonal timescale and conditions during the flood onset month. Figure 8a shows the RR given SPEI0 threshold values ( $x$ axis) conditional to seasonal SPEI values (SPEI1 $>0$, red solid; SPEI1 $>1$, red dashed; SPEI3 $>0$, green solid; SPEI3 $>1$, green dashed; SPEI6 $>0$, blue solid; SPEI6 $>1$, blue dashed). For each of these lines the confidence intervals are given in Fig. 8b-g. The RR of F and NF events increases when seasonal SPEI thresholds increase (dashed lines vs. solid lines). Compared to Fig. 7, the probabilities are higher, showing that taking into account both the conditions during the months that preceded the flood (SPEI1 to SPEI6) and the conditions during the flood onset month (SPEI0) results in even higher increased flooding likelihoods. In this case, the maximum values are found when SPEI0 exceeds 2 and the seasonal SPEI thresholds are above 1 (dashed lines). For instance, using SPEI6 $>1$, it is 14 times more likely to flood. The combination of SPEI1 $>1$ and SPEI0 exhibits the highest RR up to the SPEI0 threshold of 1.5, where it becomes 9 times more likely to have a flood event. Although the confidence intervals are relatively wide due to the variability of the two samples, in all cases the results are statistically significant when SPEI0 $<2.5$.

Finally, we present the RR for combinations of PRE7 and seasonal SPEI thresholds (SPEI1 $>0$, red solid; SPEI1 > 1, red dashed; SPEI3 $>0$, green solid; SPEI3 $>1$, green dashed; SPEI6 $>0$, blue solid; SPEI6 $>1$, blue dashed) in Fig. 9a and their corresponding confidence intervals in Fig. 9b-g. Again, we see that for increasing thresholds, it becomes more likely to have an $\mathrm{F}$ event compared to a NF event. The maximum RR values observed are 6 and 4.8, when PRE7 is higher than 2 and SPEI3 and SPEI6 higher than 1 respectively. For most conditions (except for the cases where SPEI $>1$ and SPEI6 $>1$ ) when PRE7 $<3$, the results are statistically significant. This figure shows that the combination of short-term (PRE7) and long-term conditions (SPEIs) leads to a higher RR, indicating an increased likelihood to encounter an $\mathrm{F}$ event, when thresholds are higher. As before, in both Figs. 8 and 9, the decrease in the RR and its confidence intervals for SPEI0 and PRE7 values larger than 2.5 is attributed to a statistical artifact.

\section{Discussion}

\subsection{Role and limitations of the weather-scale conditions}

The role of weather-scale meteorological conditions (particularly rainfall) in flood generation is generally accepted (Webster et al., 2011; Jongman et al., 2014; Froidevaux et al., 2015). Our results showed that the flood events were preceded by 7-day precipitation (PRE7) of similar magnitude compared to the maximum observed 7-day precipitation during the same month in the no-flood years. This indicates that although PRE7 was high, it is not able to fully justify the flood generation by itself, leading us to hypothesize that there should be other factors, other than intense rainfall, that have led to the flood event. Alternatively, inaccuracies in the data used (i.e. reanalysis datasets, disaster database) can also be (partly) of influence for not finding a strong relation between PRE7 and flood events.

Despite the absence of high-quality daily precipitation datasets in Africa (Lorenz and Kunstmann, 2012; Zhang et al., 2013), precipitation reanalysis data offer valuable information over poorly monitored regions such as subSaharan Africa (Zhan et al., 2016). However, due to the lack of valuable ground-based precipitation records, especially in developing countries, the reliability of precipitation extremes in reanalysis datasets over land varies in location and time period and it can be very sensitive to reanalysis product and resolution choice (Herold et al., 2017). Particularly, the daily precipitation values on a coarse grid are largely uncertain as they do not capture local-scale convective events, which are often responsible for high-intensity precipitation and could affect our weather-scale results.

The rationale to perform the analysis over a large area around the reported flood coordinates is to deal with the uncertainty in the presented location of the reported flood and to capture the impact of the rainfall in neighbouring areas, including some upstream, which may have contributed to the flood generation mechanisms. This simplified approach was necessary because we did not have the exact delineation of the upstream area. The real world is much more complicated, as the response of hydrological systems to precipitation varies considerably depending on time and place (Eltahir and Yeh, 1999). Further studies should give this serious consideration, carrying out analyses on local spatial scales and 


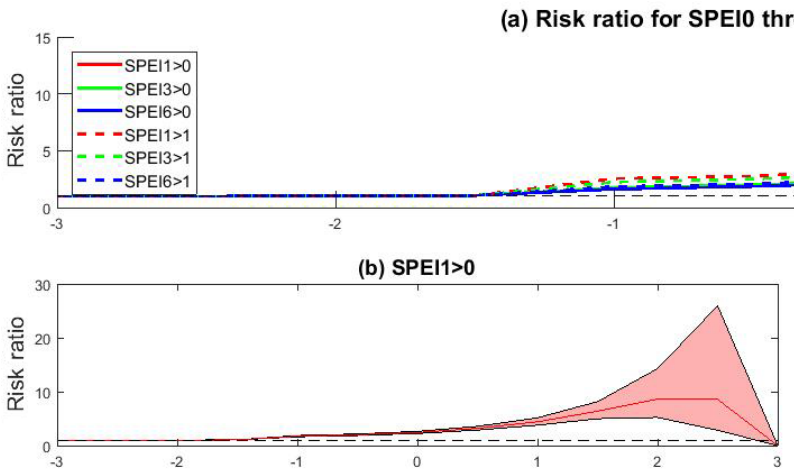

(d) SPEI3>0

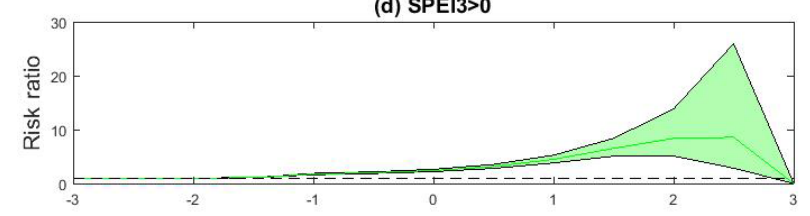

(f) SPEI6>0

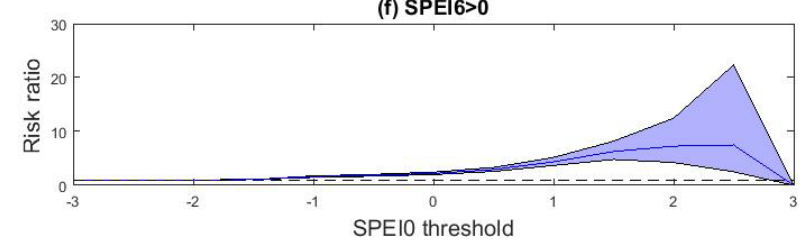

SPEIO threshold

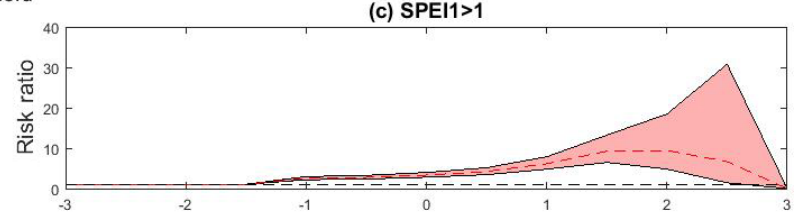

(e) $S P E I 3>1$

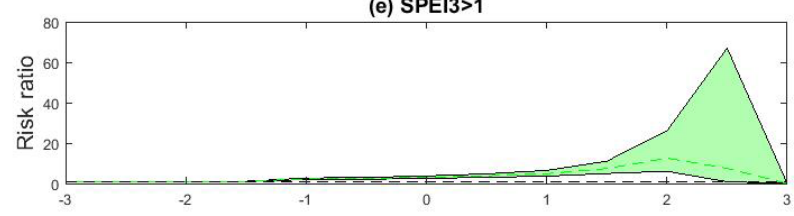

(g) SPEI6>1

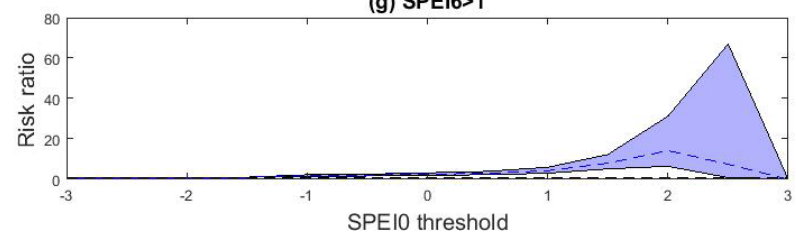

Figure 8. Risk ratio between $\mathrm{F}$ and NF for given SPEI0 thresholds conditional to seasonal SPEI values (SPEI1 > 0, red solid; SPEI $>1$, red dashed; SPEI3 > 0, green solid; SPEI3 $>$ 1, green dashed; SPEI6 $>0$, blue solid; SPEI6 $>$ 1, blue dashed) (a) and their confidence intervals are shown $(\mathbf{b}-\mathbf{g})$. The horizontal dashed line shows the risk ratio of 1.

using hydrological models to estimate the travel and the concentration time of the upstream rainfall for each flood location.

Finally, in order to gain insight into the uncertainty of the flood onset date, we compared the maximum 7-day precipitation (MAX7) during the onset month of each flood with PRE7. The median of MAX7 was found to be significantly higher. This indicates that the 7 days prior to the reported onset date (PRE7) do not always exhibit the highest precipitation during the flood month, as one might have expected. This means that either the flood reported date was not accurate or that the MAX7 worked complementary to PRE7 leading to the flood generation (i.e. flooding was already triggered before the maximum 7-day precipitation had taken place). Again, focusing on a local scale, getting accurate information on the onset date, precipitation, discharges, etc. would be an important addition in future research.

\subsection{Role of seasonal-scale conditions}

Our results showed that the most reported floods were preceded by relatively wet seasonal conditions, as their SPEIs were greater than 0 (SPEI1-70\%, SPEI3-65\%, SPEI6-57\%). Comparing the seasonal SPEI value of $F$ events to that of NF events, we see that the median of the first is significantly higher than that of the latter across the different seasonal timescales (SPEI1 to SPEI6), indicating that - in general SPEI could have served as an early warning indicator, in the case it had been monitored or forecasted. However, the median SPEI of floods goes towards climatological conditions for longer accumulation periods. This should be considered together with the decreasing forecast skill over the lead time (Molteni et al., 2011) in order to identify whether and at which point SPEI could be used as a flood warning indicator.

In a quantification of the flooding likelihood, we used for the first time in a flood risk research the RR, which is widely used in medical and epidemiology studies, comparing the likelihood of $\mathrm{F}$ events to NF events under various SPEI thresholds. When using a threshold of 1.5 for SPEI1 and SPEI3, we found a RR of 2.5, indicating an increased probability to encounter an $\mathrm{F}$ event. Although this number is not high, and the confidence intervals are quite wide, it is still first evidence that seasonal parameters could be used in flood warning systems. Using a threshold of 2 for SPEI0, which refers to the conditions during the flood onset month, the RR becomes 6.5. This shows that SPEI0 has captured in several cases the unusually wet conditions during the flood and that it could be used as a flood monitoring tool.

Finally, by bringing together the short- and the longterm conditions, we saw that the conditions during different timescales could possibly be used complementary to each 
(a) Risk ratio for PRE7 thresholds conditional to seasonal SPEI values

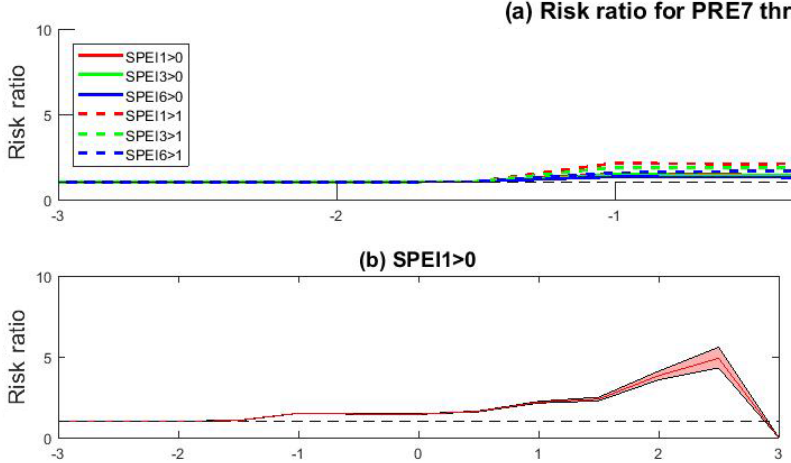

(d) $\mathrm{SPEI} 3>0$

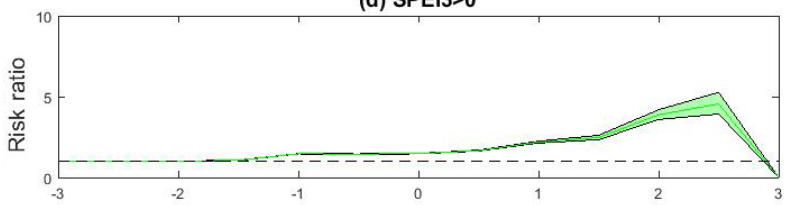

(f) SPEI6>0

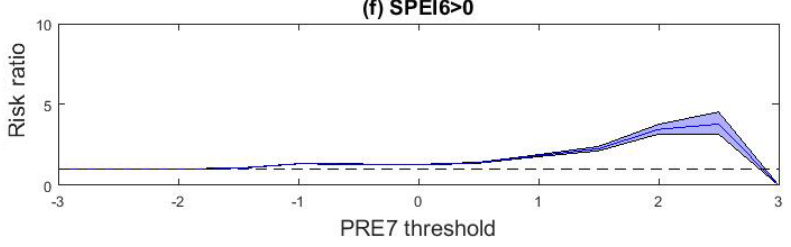

PRE7 threshold

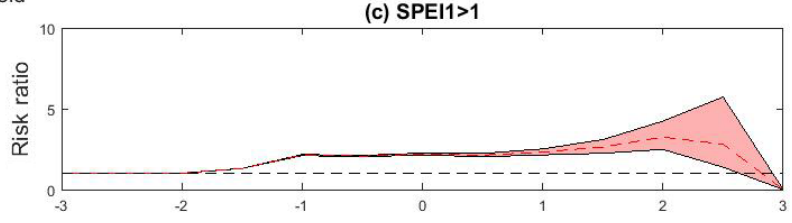

(e) SPEI3>1

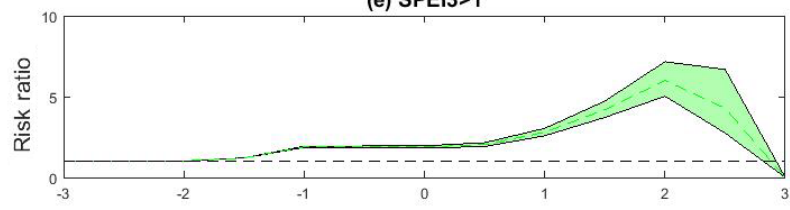

(g) SPEI6>1

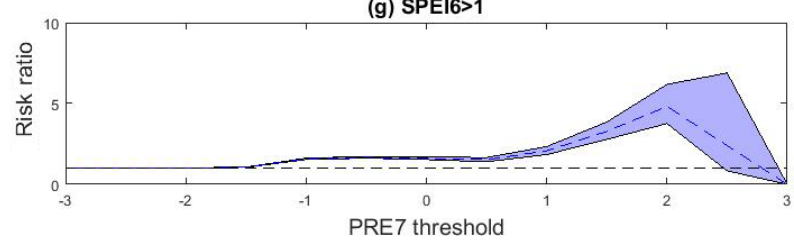

Figure 9. Risk ratio between $\mathrm{F}$ and NF for given PRE7 thresholds conditional to seasonal SPEI values (SPEI1 > 0, red solid; SPEI $>1$, red dashed; SPEI3 $>$ 0, green solid; SPEI3 $>$ 1, green dashed; SPEI6 $>0$, blue solid; SPEI6 $>$ 1, blue dashed) (a) and their confidence intervals are shown $(\mathbf{b}-\mathbf{g})$. The horizontal dashed line shows the risk ratio of 1.

other for flood warning. Using thresholds for both seasonal SPEIs and SPEI0, the likelihood of having an F event compared to an NF event is considerably increased compared to the same likelihood when taking into account only weatheror seasonal-scale conditions. For instance, when SPEI0 is above 2 and SPEI1, SPEI3 and SPEI6 are above 1, the RR becomes around 10, 12 and 14 times. Nevertheless, SPEI0 refers to the entire month when the flood was reported and not to the conditions that preceded its generation. Therefore, an early warning system could monitor rainfall and temperature observations, getting ready when the previous 3 months have had a high SPEI, and taking further action if the upcoming month is forecasted to also have a high SPEI.

On the other hand, when connecting PRE7 with seasonal SPEIs, the RR did not exhibit such high values as before. However, there is still considerably increased probability of having an F compared to an NF event (e.g. RR is 6, when PRE7 $>2$ and SPEI3 $>1$ ), demonstrating that in many reported floods seasonal-scale conditions created flood-favourable conditions, which were turned into flood events by the high PRE7. This result stresses the significance of a joint evaluation of weather and seasonal conditions in flood risk assessments.

Our findings are in line with those of Berthet et al. (2009), who demonstrated that the variety in preceding moisture plays a major role in flood generation in France at simi- lar levels of flood-triggering precipitation, and with Nied et al. (2014), who showed that a small amount of rainfall can result in flood generation when the soil is saturated. The combination of weather- and seasonal-scale condition is also supported by Pathiraja et al. (2012), who showed that there was an underestimation of the magnitude of flood flows in the Murray-Darling Basin in Australia when the joint influence of flood-producing rain events and antecedent wetness was not taken into consideration. Nevertheless, performing a more detailed analysis focusing on a (sub-)catchment area, including ground observations and the use of a hydrological model, could provide more information regarding the antecedent conditions.

\subsection{Uncertainty in disaster database}

In this research we followed a pragmatic analysis using reported damaging flood events in sub-Saharan Africa from the NatCatSERVICE database. Natural disaster databases are lacking standardized procedures in monitoring and collection of disaster loss data and therefore, numerous biases and wide disparities in the number and type of disasters is observed among them (Wirtz and Below, 2009; Gall et al., 2009). For this reason, we did not perform any cross-validation and we chose to use events only from one database for the sake of consistency. NatCatSERVICE provided the highest number 
of reported events and also provided georeferenced data and onset dates, which were necessary for the analysis.

Uncertainties regarding the accuracy of the reported onset date and the exact place of the event exist, as these datasets are often susceptible to human errors and omissions (Jongman et al., 2015). However, the fact that the median value of SPEI0 exhibits high values is evidence that the flood locations and the onset months are correct. Furthermore, in the dataset used, there is an increasing trend in flood numbers over the years, which may be caused by an upward trend in reporting frequency rather than occurrence frequency. So, regarding the NF cases that are used in this analysis, we should acknowledge that we cannot declare with certainty that a flood did not occur, as it is likely that they were not reported (e.g. omission in the dataset, not significant impact). So, by considering only the damaging reported floods, we expect that our results are useful to the humanitarian organizations, which are more interested in the catastrophic events.

We acknowledge that our sample (501 events) is small, and this might be one of the reasons that we did not manage to find any statistically significant results between different geographical areas. Conducting the analysis in local-scale flood-prone areas, and identifying different types of floods, could be a step forward for further improving the approach developed in this study. Nevertheless, to our knowledge, this is the first study that analyses the preconditions of so many historical flood events, trying to link the reality with physical parameters.

\subsection{Policy relevance}

The approach applied in this study fits well in the global policy on disaster management: the Sendai Framework of Disaster Risk Reduction (SFDRR) (UNISDR, 2015). The framework calls for enhanced efforts to reduce risk from natural hazards (including floods), such as protection, financial risk transfer and early warning systems (Mysiak et al., 2016). Seasonal forecasting systems are promising measures that can complement existing warning systems, and support post disaster risk reduction strategies such as relief operations. For this, the SPEI-based approach of using seasonal information to prepare for flood events could be further developed and tested, having as an overall target to support disaster preparedness activities in the regions at risk. For example, it could be a useful tool in the forecast-based financing approach, which is currently being developed by the Climate Centre of the Red Cross/Red Crescent (Coughlan De Perez et al., 2015) and aims to disburse funding based on forecast information. The idea behind it is to take action based on the progressively increasing flood warning information. This could be implemented by the "Ready-Set-Go" concept (Goddard et al., 2014), where each case of disaster preparedness is activated when the output of different forecast types (e.g. seasonal, weather) exceeds a certain threshold. In this case, such a threshold could be based on SPEI values as presented in this paper.

\section{Conclusions}

This paper explores the influence of antecedent conditions of reported damaging floods in sub-Saharan Africa from 1980 to 2010. Our analysis follows a pragmatic approach, being based on 501 large-scale reported floods taken from Munich Re's NatCatSERVICE disaster database. While most studies base their analyses on modelled discharges and floods, this research tries to link a considerable amount of real events to physical parameters that have contributed to their generation. We have examined both separately and together the impact of short- and long-term antecedent conditions prior to each event. To do so, we have clearly distinguished the flood antecedent conditions between weather and seasonal scales. The weather-scale conditions encompass 0-6 days prior to each flood onset date and are captured by the 7-day accumulated precipitation (PRE7), while the seasonal-scale conditions are reflected in the values of the SPEI at 1, 3 and 6 months before each flood event.

Taking into account all reported flood events, the results indicate that although PRE7 prior to flood generation was high, it did not exhibit any statistically significant differences with maximum 7-day precipitation during the same months in the no-flood years. On the other hand, the median of the maximum 7-day precipitation during the flood onset month (MAX7) was significantly higher than PRE7, which shows that, in several cases, a severe rainfall event occurred during the flood onset month and might have served complementary to PRE7 for the flood generation. Although the outcomes demonstrate the catalytic role of hydro-meteorological phenomena in flood generation during the days close to the flood onset, emphasizing the importance of weather forecasts in flood forecasting, we have seen that severe precipitation events do not always lead to flood generation.

On the seasonal scale, high SPEIs values are associated with flooding, denoting wet conditions across the different timescales before the flood event. Having disengaged seasonal from weather-scale conditions, seasonal SPEIs do not include short-term precipitation before the flood event, implying that there should be other factors that relate SPEI to flooding. Given the long accumulation periods used (i.e. 1 to 6 months) this factor could be the soil saturation of each place, probably because of limited water storage capacity. Setting a threshold of seasonal SPEI $>1.5$, we find that the RR for SPEI1 and SPEI3 becomes 2.5, demonstrating the increased likelihood of having a flood compared to a no-flood event, and providing evidence that seasonal parameters should not be excluded a priori from flood warning systems. When using SPEI0 $>2$ the RR is 6 , showing that SPEI0, which represents the conditions during the flood on- 
set month, has captured the unusually wet conditions and that it could be used as a flood monitoring tool.

The combined analysis of weather- and seasonal-scale flood antecedent conditions reveals that their joint influence affects flood generation, exhibiting higher RR than when taking into account either PRE7 or SPEI. Exploring various combinations of weather- and seasonal-scale thresholds, the results show that the RRs further increase with increasing thresholds. Translating them into practice, we conclude that decision makers should not neglect the degree of seasonal-scale wetness, as this could be a useful addition to the weather-scale flood forecasts based on which disaster actions are to be taken.

If this approach is further developed and tested, it could be used by early warning systems to set up operational programming and take action before flood events. First, if SPEI6, SPEI3 and SPEI1 are monitored, people could take preparation actions when local thresholds are exceeded, knowing that the likelihood of flooding is slightly elevated for the coming months. Once they see that the observations from the past season show high SPEIs, then they can check forecasts for the SPEI of the coming month, and 7-day rainfall forecasts, to take additional preparedness actions if those also show high values. Although the risk of acting in vain will still exist, a system based on this combination of observations and forecasts could instigate major preparedness, increasing the probabilities of a correct hit. In order to enable such a system, both monitoring and forecasts of local SPEIrelated indicators tailored to specific river basins should be made available.

Data availability. The dataset used in this paper is not publicly available. It belongs to Munich Reinsurance Company and access should be requested.

\section{The Supplement related to this article is available online at https://doi.org/10.5194/nhess-18-271-2018- supplement.}

Competing interests. The authors declare that they have no conflict of interest.

Acknowledgements. We thank Munich $\mathrm{Re}$ for providing reported flood data from the NatCatSERVICE database for the IMPREX project. This project was funded by NWO VICI grant no. 016.140 .067 , by NWO grant no. $869-15001$, by FP7 project Earth2Observe grant no. 603608 and by UK Natural Environment Research Council (NE/P000525/1).

Edited by: Bruno Merz

Reviewed by: two anonymous referees

\section{References}

Abramopoulos, F., Rosenzweig, C., and Choudhury, B.: Improved ground hydrology calculations for global climate models (GCMs) - soil water movement and evapotranspiration, J. Climate, 1, 921-941, https://doi.org/10.1175/15200442(1988)001<0921:IGHCFG>2.0.CO;2, 1988.

Aerts, J. C. J. H., Botzen, W. J. W., Emanuel, K., Lin, N., and De Moel, H.: Evaluating flood resilience strategies for coastal megacities, Science, 344, 1-3, https://doi.org/10.1126/science.1248222, 2014.

Alfieri, L., Salamon, P., Pappenberger, F., Wetterhall, F., and Thielen, J.: Operational early warning systems for waterrelated hazards in Europe, Environ. Sci. Policy, 21, 35-49, https://doi.org/10.1016/j.envsci.2012.01.008, 2012.

Balsamo, G., Albergel, C., Beljaars, A., Boussetta, S., Brun, E., Cloke, H., Dee, D., Dutra, E., Muñoz-Sabater, J., Pappenberger, F., de Rosnay, P., Stockdale, T., and Vitart, F.: ERAInterim/Land: a global land surface reanalysis data set, Hydrol. Earth Syst. Sci., 19, 389-407, https://doi.org/10.5194/hess-19389-2015, 2015.

Berthet, L., Andréassian, V., Perrin, C., and Javelle, P.: How crucial is it to account for the antecedent moisture conditions in flood forecasting? Comparison of event-based and continuous approaches on 178 catchments, Hydrol. Earth Syst. Sci., 13, 819831, https://doi.org/10.5194/hess-13-819-2009, 2009.

Bouwer, L. M., Crompton, R. P., Faust, E., Hoppe, P., and Pielke, R. A.: Disaster management. Confronting disaster losses, Science, 318, 753, https://doi.org/10.1126/science.1149628, 2007.

Braman, L. M., van Aalst, M. K., Mason, S. J., Suarez, P., Ait-Chellouche, Y., and Tall, A.: Climate forecasts in disaster management: Red Cross flood operations in West Africa, 2008, Disasters, 37, 144-164, https://doi.org/10.1111/j.14677717.2012.01297.x, 2013.

Coughlan de Perez, E., Monasso, F., van Aalst, M., and Suarez, P.: Science to prevent disasters, Nat. Geosci., 7, 78-79, https://doi.org/10.1038/ngeo2081, 2014.

Coughlan de Perez, E., van den Hurk, B., van Aalst, M. K., Jongman, B., Klose, T., and Suarez, P.: Forecast-based financing: an approach for catalyzing humanitarian action based on extreme weather and climate forecasts, Nat. Hazards Earth Syst. Sci., 15, 895-904, https://doi.org/10.5194/nhess-15-895-2015, 2015.

Coughlan de Perez, E., Stephens, E., Bischiniotis, K., van Aalst, M., van den Hurk, B., Mason, S., Nissan, H., and Pappenberger, F.: Should seasonal rainfall forecasts be used for flood preparedness?, Hydrol. Earth Syst. Sci., 21, 4517-4524, https://doi.org/10.5194/hess-21-4517-2017, 2017.

Daly, L. E.: Confidence limits made easy: interval estimation using a substitution method., Am. J. Epidemiol., 147, 783-790, https://doi.org/10.1093/oxfordjournals.aje.a009523, 1998.

Di Baldassarre, G., Montanari, A., Lins, H., Koutsoyiannis, D., Brandimarte, L., and Blöschl, G.: Flood fatalities in Africa: from diagnosis to mitigation, Geophys. Res. Lett., 37, L22402, https://doi.org/10.1029/2010GL045467, 2010.

Douben, K. J.: Characteristics of river floods and flooding: a global overview, 1985-2003, in: Irrigation and Drainage, 55, S9-S21, https://doi.org/10.1002/ird.239, 2006.

Du, J., Fang, J., Xu, W., and Shi, P.: Analysis of dry/wet conditions using the standardized precipitation index and its 
potential usefulness for drought/flood monitoring in Hunan Province, China, Stoch. Env. Res. Risk A., 27, 377-387, https://doi.org/10.1007/s00477-012-0589-6, 2013.

Dutra, E., Di Giuseppe, F., Wetterhall, F., and Pappenberger, F.: Seasonal forecasts of droughts in African basins using the Standardized Precipitation Index, Hydrol. Earth Syst. Sci., 17, 23592373, https://doi.org/10.5194/hess-17-2359-2013, 2013.

Edossa, D. C., Woyessa, Y. E., and Welderufael, W. A.: Analysis of droughts in the central region of South Africa and their association with SST anomalies, Int. J. Atmos. Sci., 2014, 1-8, https://doi.org/10.1155/2014/508953, 2014.

Eltahir, E. A. B. and Yeh, P. J. F.: On the asymmetric response of aquifer water level to floods and droughts in Illinois, Water Resour. Res., 35, 1199-1217, https://doi.org/10.1029/1998WR900071, 1999.

EM-DAT: The Emergency Events Database - Université catholique de Louvain (UCL) - CRED, edited by: Guha-Sapir, D., Brussels, Belgium, - www.emdat.be (last accessed on: 16 January 2018), 2017.

Fan, Y. and van den Dool, H.: A global monthly land surface air temperature analysis for 1948-present, J. Geophys. Res.-Atmos., 113, D01103, https://doi.org/10.1029/2007JD008470, 2008.

Froidevaux, P., Schwanbeck, J., Weingartner, R., Chevalier, C., and Martius, O.: Flood triggering in Switzerland: the role of daily to monthly preceding precipitation, Hydrol. Earth Syst. Sci., 19, 3903-3924, https://doi.org/10.5194/hess-19-3903-2015, 2015.

Fundel, F. and Zappa, M.: Hydrological ensemble forecasting in mesoscale catchments: sensitivity to initial conditions and value of reforecasts, Water Resour. Res., 47, W09520, https://doi.org/10.1029/2010WR009996, 2011.

Gall, M., Borden, K. A., and Cutter, S. L.: When do losses count?, B. Am. Meteorol. Soc., 90, 799-809, https://doi.org/10.1175/2008BAMS2721.1, 2009.

Goddard, L., Baethgen, W. E., Bhojwani, H., and Robertson, A. W.: The International Research Institute for Climate \& Society: why, what and how, Earth Persp., 1, 10, https://doi.org/10.1186/21946434-1-10, 2014.

Golnaraghi, M.: Institutional Partnerships in Multi-Hazard Early Warning Systems: a Compilation of Seven National Good Practices and Guiding Principles, Springer Science \& Business Media, Berlin Heidelberg, 2012.

Guerreiro, M. J., Lajinha, T., and Abreu, I.: Flood Analysis with the Standardized Precipitation Index (SPI), Rev. da Fac. Ciênca e Tecnol. Porto, 4, 8-14, 2008.

Herold, N., Behrangi, A., and Alexander, L. V.: Large uncertainties in observed daily precipitation extremes over land, J. Geophys. Res.-Atmos., 122, 668-681, https://doi.org/10.1002/2016JD025842, 2017.

Hoeppe, P.: Trends in weather related disasters - consequences for insurers and society, Weather Clim. Extrem., 11, 70-79, https://doi.org/10.1016/j.wace.2015.10.002, 2016.

Jongman, B., Ward, P. J., and Aerts, J. C. J. H.: Global exposure to river and coastal flooding: long term trends and changes, Global Environ. Chang., 22, 823-835, https://doi.org/10.1016/j.gloenvcha.2012.07.004, 2012.

Jongman, B., Hochrainer-Stigler, S., Feyen, L., Aerts, J. C. J. H., Mechler, R., Botzen, W. J. W., Bouwer, L. M., Pflug, G., Rojas, R., and Ward, P. J.: Increasing stress on disaster-risk fi- nance due to large floods, Nat. Clim. Change, 4, 264-268, https://doi.org/10.1038/nclimate2124, 2014.

Jongman, B., Winsemius, H. C., Aerts, J. C. J. H., Coughlan de Perez, E., van Aalst, M. K., Kron, W., and Ward, P. J.: Declining vulnerability to river floods and the global benefits of adaptation, P. Natl. Acad. Sci. USA, 112, E2271-E2280, https://doi.org/10.1073/pnas.1414439112, 2015.

Katz, K. A.: The (relative) risks of using odds ratios, Arch. Dermatol., 142, 761-4, https://doi.org/10.1001/archderm.142.6.761, 2006.

Kellett, J. and Caravani, A.: Financing Disaster Risk Reduction. A 20 year Story of International Aid, GFDRR and ODI, London, 60 pp., 2013.

Kron, W., Steuer, M., Löw, P., and Wirtz, A.: How to deal properly with a natural catastrophe database - analysis of flood losses, Nat. Hazards Earth Syst. Sci., 12, 535-550, https://doi.org/10.5194/nhess-12-535-2012, 2012.

Lorenz, C. and Kunstmann, H.: The hydrological cycle in three state-of-the-art reanalyses: intercomparison and performance analysis, J. Hydrometeorol., 13, 1397-1420, https://doi.org/10.1175/JHM-D-11-088.1, 2012.

Mckee, T. B., Doesken, N. J., and Kleist, J.: The relationship of drought frequency and duration to time scales, in: Proceedings of the 8th Conference of Applied Climatology, 17-22 January, Anaheim, CA, American Meterological Society, Boston, MA, 179-184, 1993.

Merz, R., Blöschl, G., and Parajka, J.: Spatio-temporal variability of event runoff coefficients, J. Hydrol., 331(3-4), 591-604, https://doi.org/10.1016/j.jhydrol.2006.06.008, 2006.

Molteni, F., Stockdale, T., Balmaseda, M., Balsamo, G., Buizza, R.,Ferranti, L., Magnusson, L., Mogensen, K., Palmer, T., and Vitart, F.: The New ECMWF Seasonal Forecast System (System 4), European Centre for Medium-Range Weather Forecasts, Reading, 49, 2011.

Morris, J. A. and Gardner, M. J.: Calculating confidence intervals for relative risks (odds ratios) and standardised ratios and rates, Brit. Med. J., 296, 1313-1316, https://doi.org/10.1136/bmj.296.6632.1313, 1988.

Mossad, A. and Alazba, A. A.: Drought forecasting using stochastic models in a hyper-arid climate, Atmosphere (Basel), 6, 410-430, https://doi.org/10.3390/atmos6040410, 2015.

Munich Re: NatCatSERVICE Database (Munich Reinsurance Company, Geo Risks Research, Munich), available at www. munichre.com/natcatservice, last access: 12 October 2016, 2014.

Mysiak, J., Surminski, S., Thieken, A., Mechler, R., and Aerts, J.: Brief communication: Sendai framework for disaster risk reduction - success or warning sign for Paris?, Nat. Hazards Earth Syst. Sci., 16, 2189-2193, https://doi.org/10.5194/nhess16-2189-2016, 2016.

Nied, M., Pardowitz, T., Nissen, K., Ulbrich, U., Hundecha, Y., and Merz, B.: On the relationship between hydro-meteorological patterns and flood types, J. Hydrol., 519, 3249-3262, https://doi.org/10.1016/j.jhydrol.2014.09.089, 2014.

Parajka, J., Kohnova, S., Balint, G., Barbuc, M., Borga, M., Claps, P., Cheval, S., Dumitrescu, A., Gaume, E., Hlavcova, K., Merz, R., Pfaundler, M., Stancalie, G., Szolgay, J., and Blöschl, G.: Seasonal characteristics of flood regimes across the Alpine-Carpathian range, J. Hydrol., 394, 78-89, https://doi.org/10.1016/j.jhydrol.2010.05.015, 2010. 
Pathiraja, S., Westra, S., and Sharma, A.: Why continuous simulation? the role of antecedent moisture in design flood estimation, Water Resour. Res., 48, W06534, https://doi.org/10.1029/2011WR010997, 2012.

Prenger-Berninghoff, K., Cortes, V. J., Sprague, T., Aye, Z. C., Greiving, S., Głowacki, W., and Sterlacchini, S.: The connection between long-term and short-term risk management strategies for flood and landslide hazards: examples from landuse planning and emergency management in four European case studies, Nat. Hazards Earth Syst. Sci., 14, 3261-3278, https://doi.org/10.5194/nhess-14-3261-2014, 2014.

Reager, J. T., Thomas, B. F., and Famiglietti, J. S.: River basin flood potential inferred using GRACE gravity observations at several months lead time, Nat. Geosci., 7, 588-592, https://doi.org/10.1038/ngeo2203, 2014.

Rogers, D. and Tsirkunov, V.: Costs and benefits of early warning systems, J. Chem. Inf. Model., 53, 1689-1699, https://doi.org/10.1017/CBO9781107415324.004, 2010.

Schneider, U., Becker, A., Finger, P., Meyer-Christoffer, A., Rudolf, B., and Ziese, M.: GPCC Full Data Reanalysis Version 7.0 at $0.5^{\circ}$ : Monthly Land-Surface Precipitation from Rain-Gauges built on GTS-based and Historic Data, Glob. Precip. Climatol. Cent., Global Precipitation Climatology Centre (GPCC) at Deutscher Wetterdienst, https://doi.org/10.5676/DWD_GPCC/FD_M_V6_050, 2015.

Schröter, K., Kunz, M., Elmer, F., Mühr, B., and Merz, B.: What made the June 2013 flood in Germany an exceptional event? A hydro-meteorological evaluation, Hydrol. Earth Syst. Sci., 19, 309-327, https://doi.org/10.5194/hess-19-309-2015, 2015.

Seibert, M., Merz, B., and Apel, H.: Seasonal forecasting of hydrological drought in the Limpopo Basin: a comparison of statistical methods, Hydrol. Earth Syst. Sci., 21, 1611-1629, https://doi.org/10.5194/hess-21-1611-2017, 2017.

Seiler, R. A., Hayes, M., and Bressan, L.: Using the standardized precipitation index for flood risk monitoring, Int. J. Climatol., 22, 1365-1376, 2002.

Shrier, I. and Steele, R.: Understanding the relationship between risks and odds ratios, Clin. J. Sport Med., 16, 107-10, https://doi.org/10.1097/00042752-200603000-00004, 2006.

Sivapalan, M., Blöschl, G., Merz, R., and Gutknecht, D.: Linking flood frequency to long-term water balance: Incorporating effects of seasonality, Water Resour. Res., 41, 1-17, https://doi.org/10.1029/2004WR003439, 2005.

Stephens, E., Day, J. J., Pappenberger, F., and Cloke, H.: Precipitation and floodiness, Geophys. Res. Lett., 42, 10316-10323, https://doi.org/10.1002/2015GL066779, 2015.

Tall, A., Mason, S. J., Van Aalst, M., Suarez, P., Ait-Chellouche, Y., Diallo, A. A., and Braman, L.: Using seasonal climate forecasts to guide disaster management: the Red Cross experience during the 2008 West Africa floods, Int. J. Geophys., 2012, https://doi.org/10.1155/2012/986016, 2012.
Thornthwaite, C. W.: An approach toward a rational classification of climate, Geogr. Rev., 38, 55-94, https://doi.org/10.1097/00010694-194807000-00007, 1948.

Tschoengl, L., Below, R., and Guha-Sapir, D.: An Analytical Review of Selected Data Sets on Natural Disasters and Impacts, UNDP/CRED (Workshop on Improving Compilation of Reliable Data on Disaster Occurrence and Impact), Bangkok, 2006.

UNISDR: The Human Costs of Weather Related Disasters, The United Nations Office for Diaster Risk Reduction, 2015.

Vicente-Serrano, S. M., Begueria, S., and Lopez-Moreno, J. I.: A multiscalar drought index sensitive to global warming: The standardized precipitation evapotranspiration index, J. Climate, 23, 1696-1718, https://doi.org/10.1175/2009JCLI2909.1, 2010.

Webster, P. J.: Improve weather forecasts for the developing world, Nature, 493, 17-19, https://doi.org/10.1038/493017a, 2013.

Webster, P. J., Toma, V. E., and Kim, H. M.: Were the 2010 Pakistan floods predictable?, Geophys. Res. Lett., 38, L04806, https://doi.org/10.1029/2010GL046346, 2011.

White, C. J., Franks, S. W., and McEvoy, D.: Using subseasonalto-seasonal (S2S) extreme rainfall forecasts for extended-range flood prediction in Australia, IAHS-AISH P., 370, 229-234, 2015.

Wirtz, A. and Below, R.: Working paper Disaster Category Classification and peril Terminology for Operational Purposes, Context, (October), 1-20, available at: cred.be/sites/default/files/ DisCatClass_264.pdf (last access: 16 January 2018), 2009.

Xiao, M., Zhang, Q., Singh, V. P., and Chen, X.: Probabilistic forecasting of seasonal drought behaviors in the Huai River basin, China, Theor. Appl. Climatol., 128, 667-677, https://doi.org/10.1007/s00704-016-1733-x, 2017

Zhan, W., Guan, K., Sheffield, J., and Wood, E. F.: Depiction of drought oversub-Saharan Africa using reanalyses precipitation data sets, J. Geophys. Res.-Atmos., 121, 10555-10574, https://doi.org/10.1002/2016JD024858, 2016.

Zhang, J. and Yu, K. F.: What's the relative risk? A method of correcting the odds ratio in cohort studies of common outcomes, JAMA, 280, 1690-1691, https://doi.org/10.1001/jama.280.19.1690, 1998.

Zhang, Q., Körnich, H., and Holmgren, K.: How well do reanalyses represent the southern African precipitation?, Clim. Dynam., 40, 951-962, https://doi.org/10.1007/s00382-012-1423-z, 2013.

Zhang, Y., Moges, S., and Block, P.: Does objective cluster analysis serve as a useful precursor to seasonal precipitation prediction at local scale? Application to western Ethiopia, Hydrol. Earth Syst. Sci. Discuss., https://doi.org/10.5194/hess-2017-70, in review, 2017. 